\title{
Synthesis and characterization of needlelike apatitic nanocomposite with controlled aspect ratios
}

\author{
Sz-Chian Liou ${ }^{\mathrm{a}}$, San-Yuan Chen ${ }^{\mathrm{a}, *}$, Dean-Mo Liu ${ }^{\mathrm{b}}$ \\ ${ }^{a}$ Department of Materials Science and Engineering, National Chiao-Tung University, 1001 Ta-hsueh Road, Hsinchu, Taiwan 300, ROC \\ b ApaMatrix Technologies Inc., 58-7151 Moffatt Road, Richmond, BC, Canada V6 Y3G9
}

Received 13 December 2002; accepted 8 April 2003

\begin{abstract}
Calcium-deficient apatitic (cd-HA) crystals with core-shell nanostructure with needlelike shape, 5-10 nm in diameter and 20$80 \mathrm{~nm}$ in length, were prepared via an in situ formation in the presence of polyacrylic acid (PAA) under aqueous solution of different $\mathrm{pH}$ values, ranging from 9 to 11 . Nanostructure of the resulting crystals showing a core-shell configuration with a thin layer of PAA shell of about $1 \mathrm{~nm}$ thickness was investigated. Aspect ratio (AR) of the needlelike composite was found to depend on the concentration of the PAA and solution $\mathrm{pH}$. At lower solution $\mathrm{pH}$, crystal growth was inhibited, i.e., leading to a decreased AR, with increase of PAA concentration, while an increased AR was detected at higher solution $\mathrm{pH}$, suggesting a preferential growth of the cd-HA nanocrystals. Mechanism of such preferential growth was tentatively proposed and is suggested to correct PAA adsorption along the long axis of the needlelike nanoparticles.
\end{abstract}

(C) 2003 Elsevier Science Ltd. All rights reserved.

Keywords: Calcium-deficient hydroxyapatite; Poly(acrylic acid); Aspect ratio; Needlelike crystals; Nanocomposites; Preferential crystal growth

\section{Introduction}

Synthetic calcium phosphate compounds, particularly in the composition of tricalcium phosphate (TCP) $(\mathrm{Ca} / \mathrm{P}=1.5)$ and calcium hydroxyapatite $(\mathrm{Ca} / \mathrm{P}=1.67)$, have long received a great deal of attention as prime candidates for a number of biomedical applications such as orthopedics and dentistry, simply because they exhibit considerably improved biological affinity and activity to surrounding host tissues when implanted, compared to currently existing synthetic materials. Furthermore, both compositions are chemically and structurally similar to the mineral constituent of human hard tissue. However, bone mineral (natural biocrystal) has essentially a calciumdeficient apatitic (cd-HA) structure with a $\mathrm{Ca} / \mathrm{P}$ ratio of about 1.5 , which strictly speaking, is chemically and compositionally similar to TCPs, $\mathrm{Ca}_{3}\left(\mathrm{PO}_{4}\right)_{2}$, $(\mathrm{Ca} / \mathrm{P}=1.5)$ and structurally similar to stoichiometric hydroxyapatite, $\mathrm{Ca}_{10}\left(\mathrm{PO}_{4}\right)_{6}(\mathrm{OH})_{2}(\mathrm{Ca} / \mathrm{P}=1.67)$.

\footnotetext{
*Corresponding author. Tel.: +886-3-573-1818; fax: +886-35724727.

E-mail address: sychen@cc.nctu.edu.tw (S.-Y. Chen).
}

Natural biocrystals exhibit nanostructures with needlelike or rodlike shapes well arranged within the polymeric matrix, e.g., collagen, to form natural bone. Most critically, biocrystals exhibit excellent metabolic activity even when subjected to subtle environmental changes, compared to synthetic biocrystals [1-3]. The mutual interaction between the natural biocrystal and the surrounding physiological environment is not yet well-understood, but the natural biocrystals do have a more dynamic response to environment compared to synthetic materials. One of the reasons may be the poor crystalline and nanostructured features of the natural biocrystals that are formed in the ambient environment. Both structural characters give considerable dynamics to these "biocrystals" in terms of enhanced contact areas and degradation (or redeposition) property of the environment, which is essentially a structurally induced chemical and biological response. However, this is seldom seen in synthetic biocrystals, where the nanostructured and low-crystalline characters can be lost after thermal consolidation to form solid entity. This is also the reason why many biomaterial researchers employ nowadays the so-called biomimetic method, to form nanostructured apatitic crystals $[1,4-6]$. 
Recently, many advanced methods that form nanocrystal-contained composites (called nanocomposites) at ambient temperature, have become available and they have a variety of biomedical applications [7-9]. Among the existing methodologies, in situ formation of nanocomposites by forming nanoapatite crystals in the presence of polymers is one of the most attractive routes, since it avoids extensive particle agglomeration if a mechanical mixing between nanopowder and selected polymer is adapted. Kato et al. [7] studying a series of nanocrystalline hydroxyapatite/polymer composites via an in situ synthesis method, found that the crystallization of the hydroxyapatite was retarded in the presence of ionized polymers employed and they showed the crystallization is concentration-dependent; and we also found a similar concentration dependence. As an integral part of the whole project to be elucidated in this communication, we focus on the in situ synthesis of composite-type nanograde crystals, instead of pure inorganic crystals with controlled morphology as frequently reported; and here, the calcium phosphate materials with $\mathrm{Ca} / \mathrm{P}$ ratio of 1.5 were employed instead of stoichiometric hydroxyapatite, since they bear closer chemical resemblance to natural biocrystals than stoichiometric apatite.

\section{Experimental procedure}

\subsection{Sample preparation}

The starting materials used in this investigation are analytical-grade $\left(\mathrm{CH}_{3} \mathrm{COO}\right)_{2} \mathrm{Ca} \cdot x \mathrm{H}_{2} \mathrm{O}(99 \%$, Aldrich Chemical company, Inc., USA) which are used as the $\mathrm{Ca}$ source and $\mathrm{H}_{3} \mathrm{PO}_{4}(85 \%$, Riedel-deHaen, Seelze, Germany) which are used as the $\mathrm{P}$ source. After dissolving 0.015 mole $\left(\mathrm{CH}_{3} \mathrm{COO}\right)_{2} \mathrm{Ca} \cdot x \mathrm{H}_{2} \mathrm{O}$ in deionized water, adding Polyacrylic acid ( $\mathrm{Mw}$ 450000) (PAA, Aldrich Chemical company, Inc., USA) to the solution, we adjusted the setup so that $\mathrm{pH}$ takes different values. In fact, in this investigation $\mathrm{pH}$ is controlled over the range 9-11 using $5 \mathrm{~m} \mathrm{NaOH}$ solution. Phosphoric acid (0.01 mole) was then dropped into the above solution and at the same time, the sodium hydroxide solution was used to keep its $\mathrm{pH}$ at a pre-determined level throughout the synthesis procedure. The entire reaction was processed at room temperature $\left(25^{\circ} \mathrm{C}\right)$ and followed an aging time period of $16 \mathrm{~h}$. After filtering and washing with deionized water several times and after drying overnight at $80^{\circ} \mathrm{C}$, a white precipitated powder was finally obtained having the pre-determined $\mathrm{Ca} / \mathrm{P}$ ratio 1.5 , using the atomic absorption spectroscopy analysis.

\subsection{Phase analysis}

X-ray diffractometry (M18XHF, MAC Science, Tokyo, Japan) was used for identifying the crystalline phase of the synthesized compounds at $4^{\circ}, 2 \theta / \mathrm{min}$ from $20^{\circ}$ to $60^{\circ}$.

\subsection{Fourier transform infrared ray (FTIR) spectroscopy}

Fourier transform infrared ray (FTIR) spectroscopy was performed using $\mathrm{KBr}$ pellets $(2 \mathrm{mg} / 300 \mathrm{mg} \mathrm{KBr})$ on a spectrometer (Model 580, Perkin-Elmer) with a resolution of $4.00 \mathrm{~cm}^{-1}$. Infrared spectra were recorded in the range $4000-400 \mathrm{~cm}^{-1}$ to evaluate the molecular structure and phase clarification of the resulting powders.

\subsection{Transmission electron microscopy analysis}

The powder sample was ultrasonically dispersed in ethanol to form very dilute suspensions and then a few droplets were put on copper grids coated with carbon film. Microstructure observations were made using the Philips Tecnai 20 (Holland, The Nertherlands) microscope operating at $200 \mathrm{keV}$.

\section{Results and discussion}

\subsection{Phase identification}

The use of macromolecules as templating agent to manipulate the growth of inorganic crystals has been realized in many biological systems. In the presence of biological macromolecules (such as collagen), the nucleation and growth of nanocrystalline apatite to form highly organized bone minerals is one of the most fascinating processes in nature. Likewise, in the past in forming nanocrystalline apatite, some attention was paid to the control synthesis of apatitic crystals via physical approaches such as temperature control, aging, etc. [10-13].

A number of earlier studies indicated that PAA is an inhibitor for the crystallization of apatitic crystals $[7,14,15]$. Interaction between ionized PAA anions and $\mathrm{Ca}$ cations to form $\mathrm{PAA}^{-}-\mathrm{Ca}^{++}$intermediate compound delays the desired interaction of $\mathrm{P}$ and $\mathrm{Ca}$ ions in forming the apatite. In this study, the synthetic precipitate powders with a $\mathrm{Ca} / \mathrm{P}$ ratio of 1.5 (chemically determined) show a poorly crystalline apatitic identification. This is shown in Figs. 1a-c, for $\mathrm{pH}$ 9, 10, and 11, respectively, regardless of the solution $\mathrm{pH}$ range of the study. A major characteristic diffraction pattern is as follows: a peak at $2 \theta$ of $\sim 26^{\circ}$ and a broad one at $\sim 32^{\circ}$ for the powders obtained. These peaks are almost identical to those in stoichiometric microcrystalline hydroxyapatite (sm-HA), but with much poorer diffraction resolution compared to sm-HA, particularly at $2 \theta \sim 32^{\circ}$. This suggests the synthetic powders are apatitelike crystals, and hence are considered to be cd-HA. However, upon close inspection of the 


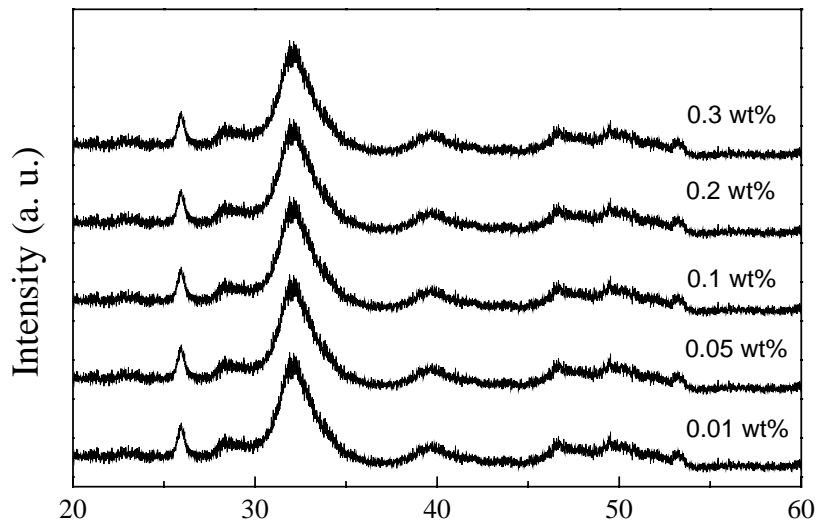

(a)

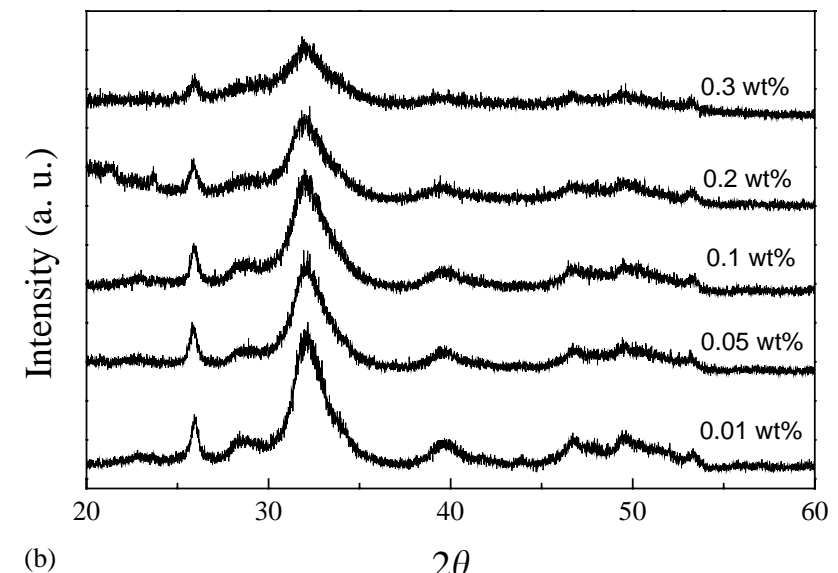

(b)

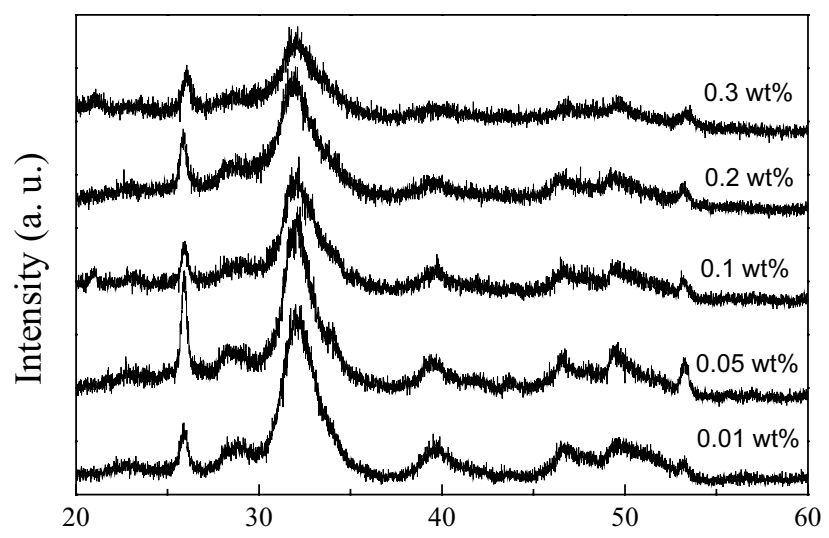

(c)

$2 \theta$

Fig. 1. X-ray diffraction patterns of the synthetic precipitate powders with different PAA concentration at (a) $\mathrm{pH} 9$, (b) $\mathrm{pH} 10$, and (c) $\mathrm{pH} 11$.

diffraction intensity of the major characteristic peak at $32^{\circ}$, it is clear that for $\mathrm{pH} 10$ and $\mathrm{pH} 11$ cases, the crystallinity of the resulting powders becomes even poorer with increasing PAA concentration while the crystallinity remains almost unchanged (i.e., similar diffraction intensity) for solution at $\mathrm{pH}=9$.

Molecular arrangement of the precipitate powders can be further identified through the use of FTIR analysis, where, as selectively shown in Fig. 2, is the IR spectra of the powders prepared in the presence of $0.05 \mathrm{wt} \%$ PAA at different solution $\mathrm{pH}$ is there. It clearly shows (1) the presence of two characteristic $v_{4}$ $\mathrm{PO}_{4}$ bands around 563 and $600 \mathrm{~cm}^{-1}$, and (2) the presence of $v_{3} \mathrm{PO}_{4}$ band in the range $1100-1000 \mathrm{~cm}^{-1}$ in all the cases, and these bands are the characteristic molecular structures in the apatitic lattice. Some carbonate groups were detected at $\sim 1400 \mathrm{~cm}^{-1}$, and one broad absorption bands at $\sim 3500 \mathrm{~cm}^{-1}$, designated hydroxyl groups. These IR spectra further confirm the apatitic structure of the powders prepared and they were identified to be cd-HA chemically and structurally. The bands in the range $1750-1450 \mathrm{~cm}^{-1}$ are assigned to the characteristic absorption peaks of PAA molecules. This observation indicates that the powders prepared in this

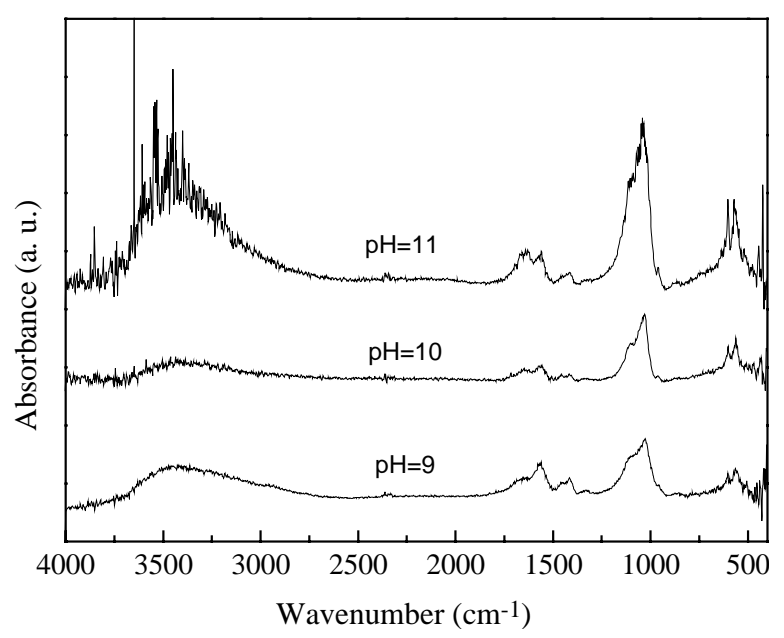

Fig. 2. FTIR spectra of the synthetic precipitate powders prepared in the presence of $0.05 \mathrm{wt} \%$ PAA at different solution $\mathrm{pH}$.

study were virtually a mixture of inorganic cd-HA crystals and organic PAA.

The decrease in diffraction intensity with increasing PAA concentration agrees with previous observations, 
where an inhibiting effect of PAA molecules on crystallization of apatite can be well explained [7,15]. Increase in PAA concentration indicates increased amount of dissociated PAA anions, i.e., carboxylic ion $(\mathrm{COO})^{-}$, in aqueous solution:

$\mathrm{PAA} \leftrightarrow \mathrm{PAA}(\mathrm{COO})^{-}+\mathrm{H}^{+}$.

A further association of $\mathrm{PAA}(\mathrm{COO})^{-}$and $\mathrm{Ca}^{++}$ results in a complex compound which can be of the simplified form:

$\mathrm{PAA}(\mathrm{COO})^{-}+\mathrm{Ca}^{++} \leftrightarrow \mathrm{PAA}(\mathrm{COO}) \mathrm{Ca}^{+}$.

Since the solutions remain clear after $\mathrm{Ca}$ ions are mixed with PAA polymer solution and no sign of precipitate or visible colloidal complex can be optically detected. According to previous investigation [7], a $\mathrm{Ca}-$ PAA(COO) complex formed rapidly in aqueous solution which further inhibits desired reaction between available $\mathrm{Ca}$ ions and phosphate ions to form crystalline apatite. This mechanism not only suppresses the formation of crystalline apatite, i.e., inhibition of nucleation, but also retards the growth of the apatitic crystals, which will be further elucidated in forthcoming analysis. For solution at $\mathrm{pH}=9$, the diffraction intensity of the characteristic peaks remains unchanged irrespective of the PAA concentration, and in a qualitative comparison, the characteristic peaks are generally stronger in intensity for solution $\mathrm{pH} 10$ and 11 than at $\mathrm{pH}=9$. This indicates a gradually degraded crystallinity of the developed cd-HA or resulting crystallites getting smaller in dimension at $\mathrm{pH} 9$.

One possible explanation of these differences in structural development under $\mathrm{pH} 9$ and under $\mathrm{pHs}$ greater than 10 is based on the degree of dissociation of the PAA. According to Reaction (1), lower $[\mathrm{OH}]$ concentration, having 1 and 2 orders of magnitude lower than those at $\mathrm{pH} 10$ and $\mathrm{pH} 11$, respectively, when PAA was dissolved in solution at $\mathrm{pH}$ 9. This enables the movement of Reaction (1) towards the left side, rather than right side, resulting in the lower concentration of the ionized $\mathrm{PAA}(\mathrm{COO})^{-}$species in the solution. Lower concentration of the PAA $(\mathrm{COO})^{-}$anions renders the $\mathrm{Ca}$ ions in the solution that chemically interacted with PAA(COO) - ions to form an intermediate complex becoming less in quantity at $\mathrm{pH} 9$ than at $\mathrm{pH} 10$ and $\mathrm{pH}$ 11. This is further evidenced by Bao et al. [16], who indicated a complete dissociation of PAA when solution $\mathrm{pH}$ is greater than 10 .

By employing the growth inhibition effect of the PAA, this investigation has a three-fold purpose: (1) to manipulate the growth of cd-HA crystals to form nanometric particles of control morphology, (2) to develop cd-HA with relatively poor crystallinity and (3) to develop cd-HA-PAA composite-type nanocrystals for subsequent synthesis of nanocomposites and this will be elucidated elsewhere.

\subsection{Powder morphology}

Fig. 3 shows the morphology of the precipitated cdHA powders at different $\mathrm{pH}$ levels. The precipitated powders show similar needlelike shape regardless of solution $\mathrm{pH}$ and the amount of PAA used. This suggests both the hydroxyl groups and PAA ions have little influence on the morphological development of the cdHA crystals. In this investigation, attention is directed more at the growth of cd-HA crystals and the experimental observation showed a strong influence on cd-HA crystal growth. Figs. $4 a-c$ show the dimensional length of the cd-HA crystals in both radial (diameter) and axial (length) directions measured in terms of different PAA concentrations at $\mathrm{pH} 9,10$, and 11, respectively, which has dimensions $5-10 \mathrm{~nm}$, diameter and $20-80 \mathrm{~nm}$, length.

A rapid decrease in the length of the needlelike nanocrystals appears in both axial and radial directions when a small amount of PAA ions is present in the solution. The reduction in dimensional length in both directions is similar, which is about $40-50 \%$ for PAA concentration from $0 \%$ to $0.01 \mathrm{wt} \%$. This observation gives direct evidence of the influence of the PAA on the crystal growth of the cd-HA nanocrystals. Further increase in PAA causes a further reduction of the resulting cd-HA crystals; however, in some cases, which are not clearly understood at present, for solutions at higher solution $\mathrm{pH}$, an increase of the length in both directions was detected when the PAA concentration is in the range $0.05-0.1 \mathrm{wt} \%$. As a general trend of the crystal growth, PAA does inhibit the growth of the cdHA nanocrystals to a considerable extent over the PAA concentration and $\mathrm{pH}$ range of study.

The aspect ratio $(\mathrm{AR}=$ length/diameter $)$ of the resulting needlelike nanocrystallites is presented in Fig. 5 with respect to the concentration of PAA at different solution pHs. The standard deviation of the AR obtained is between 0.5 and 1.6 for all the measurements, which is within the size of the symbols employed in each curve. For $\mathrm{pH} 9$, the AR is decreased gradually from 10 to 4 with increasing PAA and for $\mathrm{pH} 10$, the variation of AR is not considerable but remain in the range 5-7. However, for $\mathrm{pH} 11$, an increase in the AR from 5 to 9 appears. This suggests that the growth mechanism of the cd-HA nanocrystals is not only suppressed but is preferentially oriented in the presence of PAA molecules. This point, to our knowledge, has not been reported in the literature and it has a profound implication to the control of growth of the cd-HA crystals that have a number of biomedical and engineering uses.

The mechanism of such a preferential growth of the cd-HA needlelike nanocrystals is not fully understood. However, since the only variable in this comparison is solution $\mathrm{pH}$, it is possible to account for 


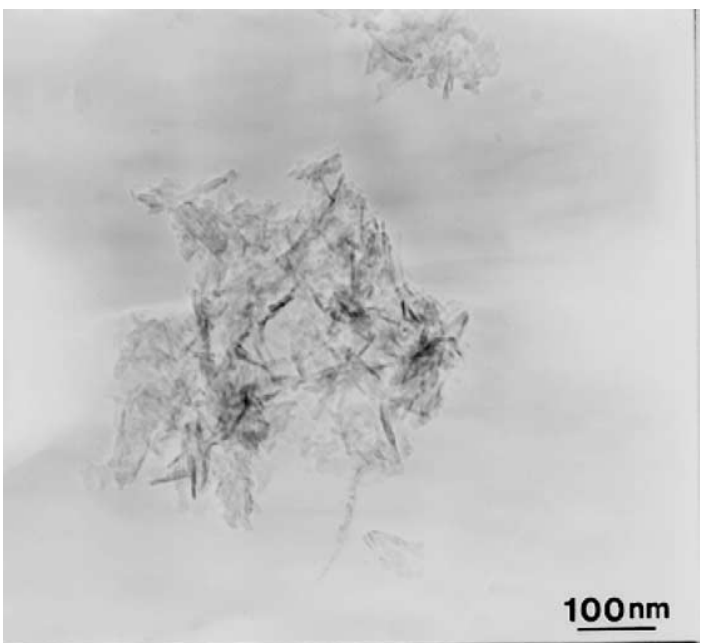

(a)

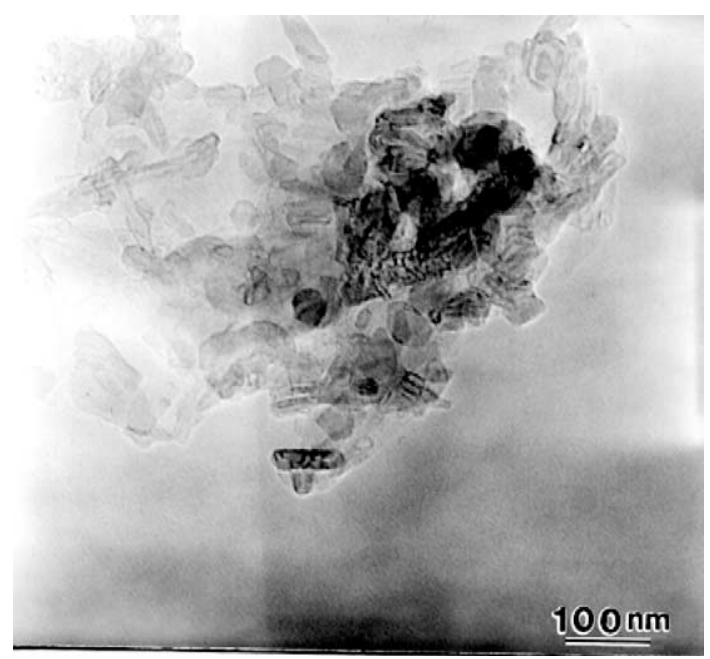

(b)

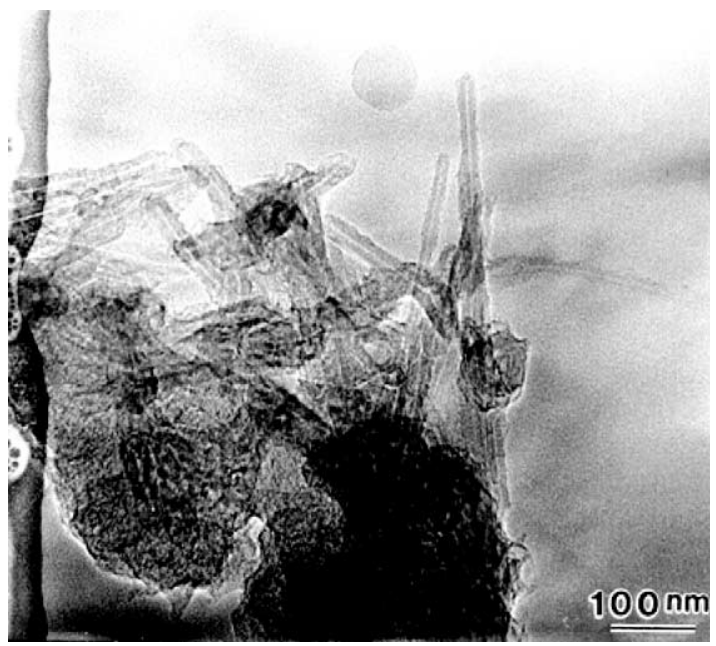

(c)

Fig. 3. The morphology of precipitated cd-HA powders at different solution $\mathrm{pH}$ : (a) $\mathrm{pH} \mathrm{9,} \mathrm{(b)} \mathrm{pH} \mathrm{10,} \mathrm{and} \mathrm{(c)} \mathrm{pH} 11$. this phenomenon in terms of the dissociation degree of PAA molecules as a result of hydroxyl concentration, i.e. $[\mathrm{OH}]$, in the solution, as mentioned in Reaction (1). Based on the observed crystal growth of the cd-HA, it is reasonable to assume that the dissociated $\mathrm{PAA}(\mathrm{COO})^{-}$ ions are preferably adsorbed onto the surface perpendicular to the radial direction of the cd-HA crystals, i.e., the $a$-axis of the lattice (schematic drawn in Fig. 6), which, for instance, has a surface area at least 10 times higher than that of the area perpendicular to the axial direction of the needle for needles with an AR above 5 . The highly negatively charged PAA ions possibly interact strongly with the surface $\mathrm{Ca}$ ions to form the intermediate compound (Reaction (2)) on the needle surface. This chelating compound causes a retardation of crystal growth more in the radial direction than in the axial direction ( $c$-axis of the lattice) of the nanoneedle, leading to higher AR of the resulting crystals. Accordingly, this can be the case of $\mathrm{pH}=11$, which, according to Reaction (1), should produce more dissociated PAA ions, or preferably, more dissociated carboxyl groups in the PAA macromolecules, giving stronger interaction with the surface.

On the other hand, at $\mathrm{pH} 9$, the population of the dissociated carboxyl groups may be reduced by $1-2$
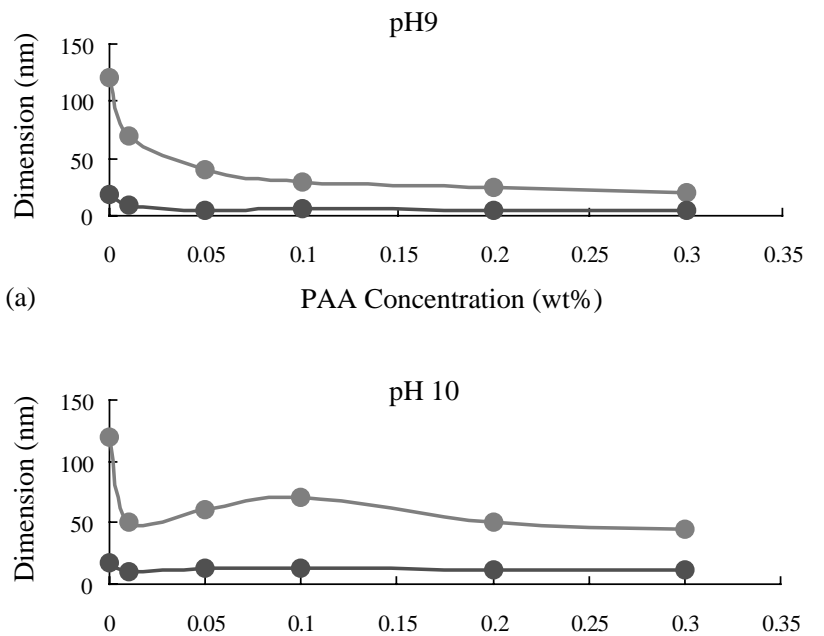

(b)

PAA Concentration (wt $\%$ )

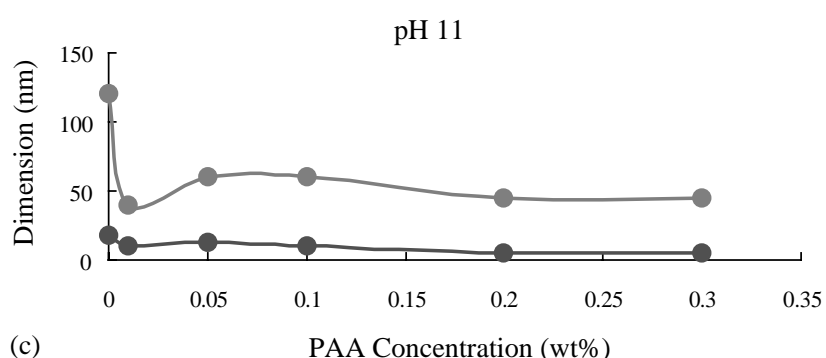

Fig. 4. The dimensional length of the cd-HA crystals in both radial and axial directions measured in different PAA concentrations at different solution $\mathrm{pH}$ : (a) $\mathrm{pH}$ 9, (b) $\mathrm{pH}$ 10, and (c) $\mathrm{pH} 11$. 


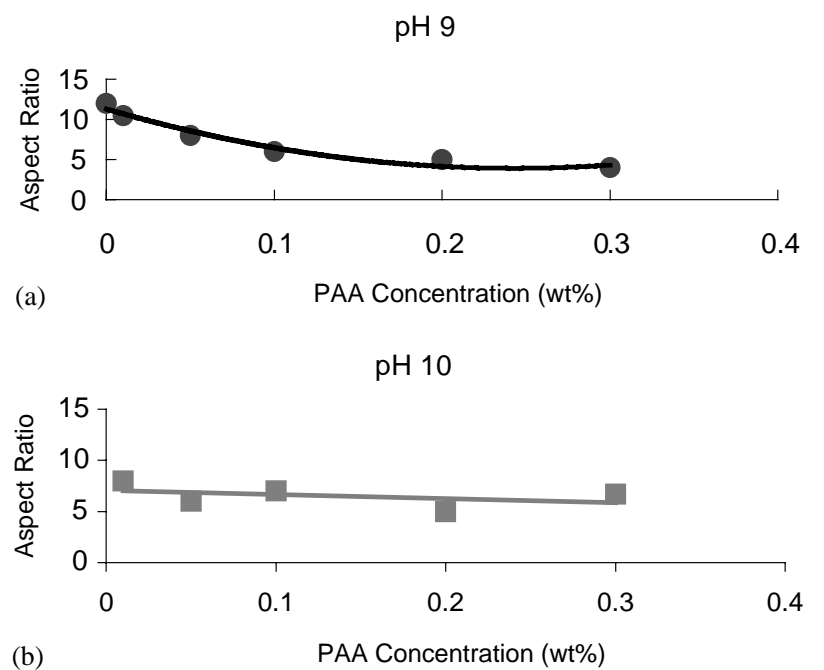

(b)

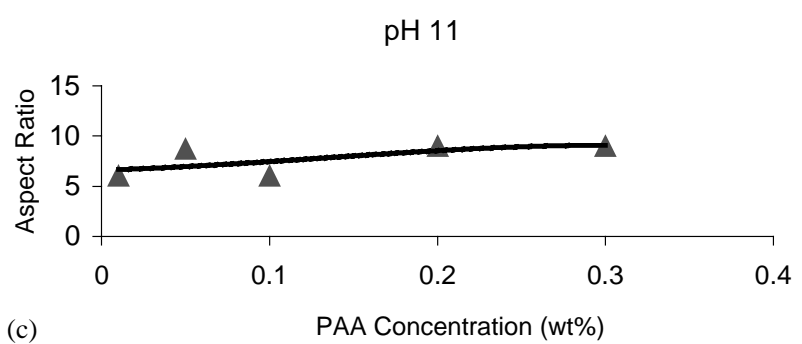

Fig. 5. The AR of the resulting needlelike nanocrystallites with respect to the concentration of PAA at different solution $\mathrm{pH}$ : (a) $\mathrm{pH}$ 9, (b) $\mathrm{pH}$ 10 , and (c) $\mathrm{pH} 11$.

orders in concentration compared to that at $\mathrm{pH} 10$ and pH 11, respectively. This may cause the macromolecular PAA ions to be less negatively charged than that at higher solution $\mathrm{pH}$. Then, lesser extent of interaction with the surface $\mathrm{Ca}$ ions on the $a$-axis of the lattice can be expected, and the potency of crystal growth in the radial direction is then not considerably suppressed, resulting in a reduced AR. It is also found from the experimental observation that at $\mathrm{pH} 10$, the growth of the cd-HA nanocrystals is not considerably different and this resulting in a similar level of AR of the final crystals, irrespective of PAA concentration. Therefore, it is more interesting to realize that a controlled morphological development of the needlelike cd-HA nanocrystals can be easily and precisely manipulated through the control of solution $\mathrm{pH}$ and the corresponding concentration of ionized PAA macromolecules. Nanocomposites with distinctly different physical properties can be manipulated based on the needlelike nanocrystals with controlled AR and orientation, and they will be further elucidated elsewhere.

\subsection{Nanostructured analysis}

High-resolution TEM showed that an axial zone in some needlelike particles can be clearly observed as in

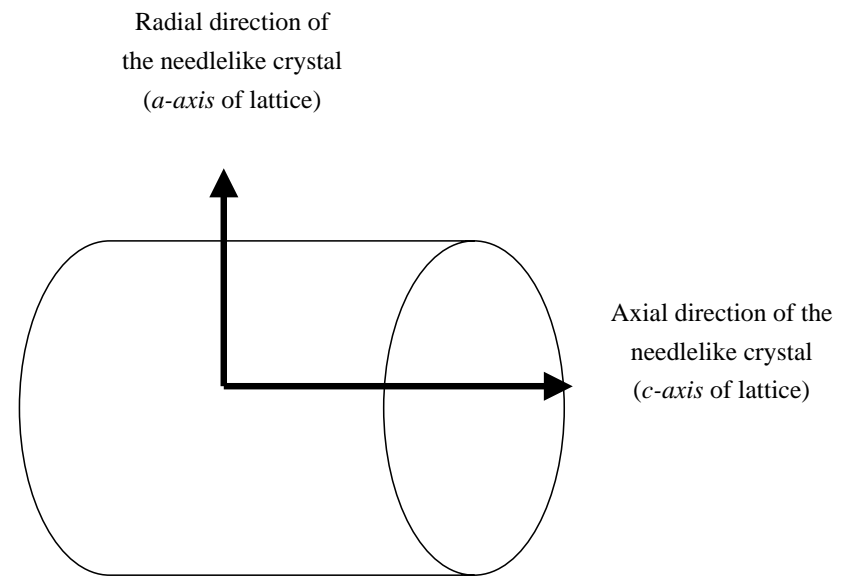

Fig. 6. Schematic illustration of the cd-HA crystals in both $a$ - and $c$ axis of the needlelike crystal.

Fig. 7. A white line dissecting the cd-HA nanocrystals in the center and through their long axis was observed in this study. The central line was seen predominantly in long needlelike crystallites parallel to (100) cd-HA lattice fringes, having a width of $0.82 \mathrm{~nm}$, and was bound by dark Fresnel-like fringes. The central defect line of the cd-HA nanocrystals is occasionally observed in this work; however, the forming mechanism has not yet been fully understood at present. Nelson et al. [17] considered that the central planar defect could be the initial nucleus during biological apatite precipitation and act as a template on later apatite precipitates.

Moreover, a thin layer of amorphous material surrounding the needle was observed and has an average thickness of about $1 \mathrm{~nm}$ along the surface of the cd-HA needle crystals. This layer is believed to be the PAA, which encapsulates the nanocrystals by either physical or chemical interaction, or combinations during synthesis, and forms a core-shell nanostructured composite.

\subsection{Thermal analysis}

While subjecting to thermal treatment, the filtered and thoroughly washed nanopowders showed similar weight loss behavior for solutions with different PAA concentrations, as representatively depicted for the case at $\mathrm{pH} 9$ in Fig. 8 (similar weight loss behavior was also observed for the cases at $\mathrm{pH} 10$ and $\mathrm{pH} 11)$. In general, the residual PAA on the cd-HA nanopowder showed a twostep weight loss; one with a slow change in the weight loss curve in the temperature range from $25^{\circ} \mathrm{C}$ to about $360^{\circ} \mathrm{C}$, corresponding to the vaporization of residual water and possibly desorption of some weakly adsorbed PAA molecules. Following the slow change in weight loss, a steeper change in the weight loss curve appears until about $500^{\circ} \mathrm{C}$, which corresponds the thermal decomposition of PAA. 


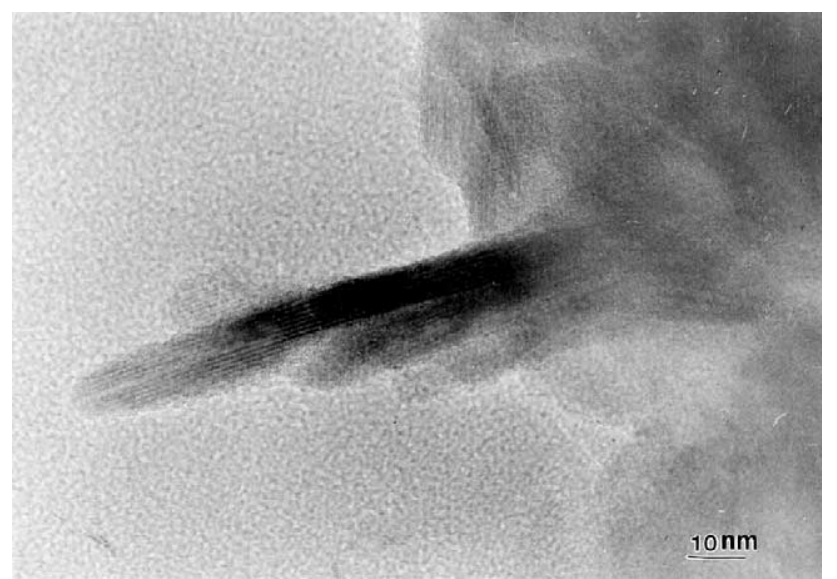

Fig. 7. High-resolution TEM image in the needlelike particle of cd-HA crystal.

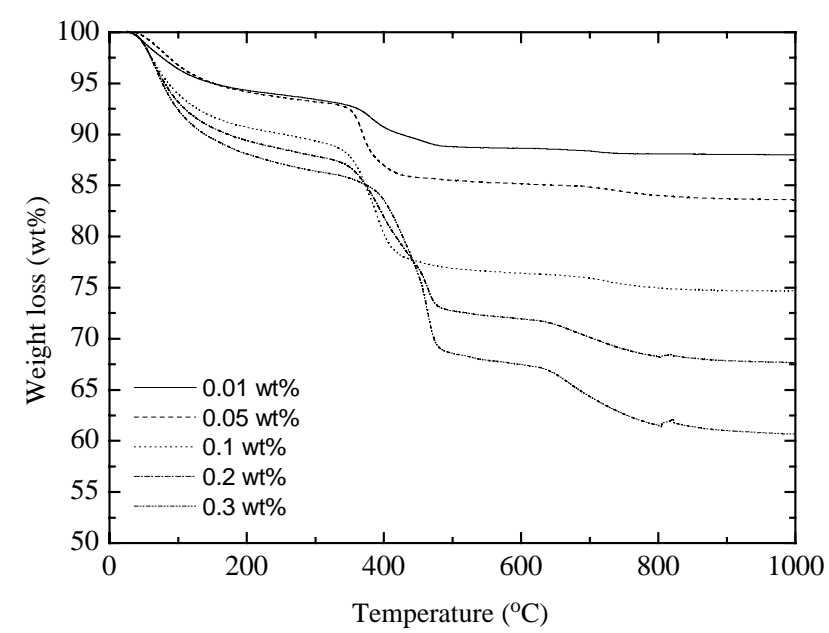

Fig. 8. The weight loss behavior of the synthetic precipitate powders prepared in solution $\mathrm{pH} 9$ with different PAA concentrations.

However, there seems no appreciable change in the weight loss curve above $500^{\circ} \mathrm{C}$ till $1000^{\circ} \mathrm{C}$, except the one with $0.3 \mathrm{wt} \%$ PAA where weight loss of $6.6 \%$ was detected. This weight loss region for the case of $0.3 \mathrm{wt} \%$ PAA can be further divided into two stages; $500-800^{\circ} \mathrm{C}$, having $5.2 \%$ loss, and $800-1000^{\circ} \mathrm{C}, 1.4 \%$ loss. Those high-temperature weight loss regions can be attributed to the pyrolytic cleavage of carboxylate-cd-HA bonds at interface and the loss of water as a result of thermal decomposition of cd-HA, to form TCP, and has been confirmed by XRD analysis (not shown) [18]. In this investigation, the possible thermal decomposition at elevated temperature resulting in water elimination can then be proposed in a simplified form, when $x=1$ :

$$
\begin{array}{r}
\mathrm{Ca}_{9}\left(\mathrm{PO}_{4}\right)_{5}\left(\mathrm{HPO}_{4}\right)(\mathrm{OH}) \\
\quad \rightarrow 3 \mathrm{Ca}_{3}\left(\mathrm{PO}_{4}\right)_{2}+\mathrm{H}_{2} \mathrm{O} .
\end{array}
$$

The elimination of water is about $2 \%$ from Reaction (3), which is slightly higher than the measured value for the case of $0.3 \mathrm{wt} \%$ PAA, suggesting partial decomposition of the cd-HA nanocrystals, resulting in a mixture of cd-HA and TCP.

However, closer inspection of the weight loss curve shown in Fig. 8, a similar but weak weight loss peak was recorded at temperatures higher than about $700^{\circ} \mathrm{C}$ for PAA of 0.05 and $0.1 \mathrm{wt} \%$, although the change in weight loss behavior was getting weaker with decreasing PAA. The XRD spectra did not show detectable phase change from cd-HA to TCP for lower PAA concentrations. However, we believed they should be some phase transformation, as detected in the case of $0.3 \mathrm{wt} \%$ PAA, but this may be far below the resolution limit of the XRD.

The increase in the weight loss at higher PAA concentration can be due to an increased adsorption amount on the surface of the nanoparticles, which in certain cases, is further associated with an increased surface area as a result of decrease in particle size with increasing PAA. This should be more pronounced for the case at $\mathrm{pH} 9$, since a continuing decrease in particle size (in both axial and radical directions) was detected with increasing PAA concentration. However, for the cases at $\mathrm{pH} 10$ and $\mathrm{pH} 11$, it is reasonable to assume that the total surface area that is available for PAA molecules to adsorb can either remain similar ( $\mathrm{pH} 10)$ because the change in particle dimension is relatively small or in some case, even decreased ( $\mathrm{pH} 11)$ because of increasing particle dimensions in the PAA between 0.01 and $0.3 \mathrm{wt} \%$ under this investigation. It is further evidenced that a saturated adsorption was detected at about $30 \%$ when the PAA is controlled at a concentration $>0.1 \mathrm{wt} \%$ for $\mathrm{pH} 11$, while a similar behavior, i.e., approaching a saturated adsorption, as depicted at $\mathrm{pH}$ 11 , was also detected at PAA $>0.2 \mathrm{wt} \%$ for $\mathrm{pH} 10$. The adsorption is continuously increased up to $32 \%$ by weight when PAA is increased up to $0.3 \mathrm{wt} \%$ in solution at $\mathrm{pH}$ 9, where the "saturated" adsorption seems to approach when PAA is approaching $0.3 \mathrm{wt} \%$ in the solution.

Based on the above findings, it shows that a "saturated" adsorption of the anionic PAA onto the cd-HA can be obtained with a critical PAA concentration relying on solution $\mathrm{pH}$; more specifically, to reach saturation adsorption, the minimum amount of the PAA in the solution is moving from a lower $(\sim 0.1 \mathrm{wt} \%)$ to a higher content $(>0.3 \mathrm{wt} \%)$ when the solution chemistry is moving from higher (11) to lower $\mathrm{pH}$ (9) level. This indicates the adsorption behavior is a strong function of solution $\mathrm{pH}$, and accordingly, is essentially a complicated function of the surface chemistry of the nanoparticles, degree of ionization of the PAA molecules, and charge state on particle surface, as previously reported $[16,19,20]$.

The increased amount of PAA adsorbed at pH 9, e.g., $2 \%(=32-30 \%)$, can be attributed to the increase in the 
surface area as a result of size reduction of the cd-HA nanoparticles prepared at $\mathrm{pH} 9$ in a given quantity of the starting precursor.

\section{Concluding remarks}

In situ forming of needlelike calcium-deficient hydroxyapatite (cd-HA) nanocrystals with a core-shell composite structure was synthesized in the presence of high molecular weight PAA. The structural development of the core-shell cd-HA nanocomposites was manipulated over an AR from 4 to 10. Experimental results indicate solution $\mathrm{pH}$ being a predominant factor for the preferential growth, and thus for the ARs of the cdHA nanocrystalline composite during microstructural evolution. The mechanism of the preferential growth was proposed and is believed to relate strongly to the preferred adsorption of the PAA anions along the surface of developing cd-HA nanocrystals. It is more instructive utilizing the needlelike cd-HA nanocrystals to form nanocomposites of different shapes for a number of biomedical and engineering applications.

\section{Acknowledgements}

The authors gratefully acknowledge the National Science Council of the Republic of China for its financial support through Contract No. NSC-91-2216E-009-025 and are also thankful to the ApaMatrix Technologies Inc. Canada, for technical supports during the period of collaboration.

\section{References}

[1] Kim HM, Kim Y, Park SJ, Rey C, Lee HM, Gimcher MJ, Ko JS. Thin-film of low crystalline calcium phosphate apatite formed at low temperature. Biomaterials 2000;21:1129-34.

[2] Legeros RZ. Calcium phosphate materials in restorative dentistry—a review. Adv Dent Res 1988;2:164-8.

[3] Hench LL. Bioceramics: from concept to clinic. J Am Ceram Soc 1991;74:1487-510.
[4] Liu DM, Yang Q, Troczynski T. In-vitro forming of calcium phosphate layer on sol-gel hydroxyapatite-coated metal substrates. J Mater Sci Mater Med 2002;13:965-71.

[5] Wen HB, De Wijn JR, Cui FZ, De Groot K. Preparation of calcium phosphate coatings on titanium implant materials by simple chemistry. J Biomed Mater Res 1998;41:227-36.

[6] Lin S, Campbell AA. US patent \#5 958 430, 1999.

[7] Kato K, Eika Y, Ikada Y. In situ hydroxyapatite crystallization for the hydroxyapatite/polymer composites. J Mater Sci Mater Med 1997;32:5533-43.

[8] Yamaguchi, Tokuchi K, Fukuzaki H, Koyama Y, Takakuda K, Monma H, Tanaka J. Preparation and microstructure analysis of chitosan/hydroxyapatite nanocomposites. J Biomed Mater Res 2001;50:20-7.

[9] Liu Q, De Wijn JR, Van Blitterswijk CA. Nano-apatite/polymer composites: mechanical and physicochemical characterization. Biomaterials 1997;18:1263-70.

[10] Ahn ES, Gleason NJ, Nakahira A, Ying JY. Nanostructure processing of hydroxyapatite-based bioceramics. NanoLett 2001; 1(3): 149-53.

[11] Akao M, Aoki H, Kato K. Mechanical properties if sintered hydroxyapatite for prosthetic applications. J Mater Sci 1981; 16:809.

[12] Jarcho M, Bolen CH, Thomas MB, Bobick J, Kat JF, Doremus RH. Hydroxylapatite synthesis and characterization in dense polycrystalline form. J Mater Sci 1976;11:2027.

[13] Fang Y, Agrawal DK, Roy DM. Fabrication of transparent hydroxyapatite ceramics by ambient-pressure sintering. Mater Lett 1995;23:147.

[14] Kamitahara M, Kawashita M, Kokubo T, Nakamura T. Effect of polyacrylic acid on the apatite formation of a bioactive ceramic in a simulated body fluid: fundamental examination of the possibility of obtaining bioactive glass-ionomer cements for orthopedic use. Biomaterials 2001;22:3191-6.

[15] Amjad Z. Performance of polymeric additives as HA crystal growth inhibitors. Phosphorus Res Bull 1995;5:1-12.

[16] Bao Y, Senos AMS, Almeida M, Gauckler LJ. Rheological behavior of aqueous suspensions of hydroxyapatite (HAP). J Mater Sci Mater Med 2002;13:639-43.

[17] Nelson DGA, Wood GJ, Barry JC, Featherstone JDB. The structure of $\left(\begin{array}{ll}1 & 0\end{array}\right)$ defects in carbonated apatite crystallites: a high resolution electron microscope study. Ultramicroscopy 1986;19: 253-66.

[18] Borozhkina EI, Dorozhkin SV. Mechanism of the solid-state transformation of a calcium-deficient hydroxyapatite (CDHA) into biphasic calcium phosphate (BCP) at elevated temperature. Chem Mater 2002;14:4267-72.

[19] Cesarmo III J, Aksay IA. Processing of highly concentrated aqueous $\alpha$-Alumina suspensions stabilized with polyelectrolytes. J Am Ceram Soc 1998;71(12):1062.

[20] Hackley VA. Colloidal processing of Silicon Nitride with poly(acrylic acid): I. adsorption and electrostatic interactions. J Am Ceram Soc 1997;80(9):2315. 